\title{
Age-Related Reversals in Neural Recruitment across Memory Retrieval Phases
}

\author{
(D)Jaclyn H. Ford and Elizabeth A. Kensinger \\ Department of Psychology, Boston College, Chestnut Hill, Massachusetts 02467
}

Over the last several decades, neuroimaging research has identified age-related neural changes that occur during cognitive tasks. These changes are used to help researchers identify functional changes that contribute to age-related impairments in cognitive performance. One commonly reported example of such a change is an age-related decrease in the recruitment of posterior sensory regions coupled with an increased recruitment of prefrontal regions across multiple cognitive tasks. This shift is often described as a compensatory recruitment of prefrontal regions due to age-related sensory-processing deficits in posterior regions. However, age is not only associated with spatial shifts in recruitment, but also with temporal shifts, in which younger and older adults recruit the same neural region at different points in a task trial. The current study examines the possible contribution of temporal modifications in the often-reported posterioranterior shift. Participants, ages 19-85, took part in a memory retrieval task with a protracted retrieval trial consisting of an initial memory search phase and a subsequent detail elaboration phase. Age-related neural patterns during search replicated prior reports of age-related decreases in posterior recruitment and increases in prefrontal recruitment. However, during the later elaboration phase, the same posterior regions were associated with age-related increases in activation. Further, ROI and functional connectivity results suggest that these posterior regions function similarly during search and elaboration. These results suggest that the often-reported posterior-anterior shift may not reflect the inability of older adults to engage in sensory processing, but rather a change in when they recruit this processing.

Key words: aging; fMRI; memory

\section{Significance Statement}

The current study provides evidence that the often-reported posterior-anterior shift in aging may not reflect a global sensoryprocessing deficit, as has often been reported, but rather a temporal modification in this processing in which older adults engage the same neural regions during a detail elaboration phase that younger adults engage during memory search. In other words, older adults may ultimately be able to engage the same processes as younger adults during some cognitive tasks when given the time to do so. Future research should examine the generalizability of this effect and the importance of encouraging older adults to engage in these processes through task instruction or questions.

\section{Introduction}

Memory complaints are common among older adults and healthy aging is associated with significant alterations in memory performance across various tasks and domains (Park et al., 2002).

Received Feb. 23, 2017; revised March 23, 2017; accepted April 17, 2017.

Author contributions: J.H.F. and E.A.K. designed research; J.H.F. performed research; J.H.F. and E.A.K. analyzed data; J.H.F. and E.A.K. wrote the paper.

This work was supported by a Memory and Cognitive Disorders grant from the McKnight Endowment Fund for Neuroscience (E.A.K.) and the National Institutes of Health (Grant MH080833 to E.A.K.). We thank Katherine Mickley Steinmetz for assistance in designing the current study; Halle Zucker and John Morris for assistance in compiling stimuli, creating presentation scripts, and running participants; and the staff of the Harvard Center for Brain Science, particularly Tammy Moran and Ross Mair, for assistance with MRI data collection and quality assurance.

The authors declare no competing financial interests.

Correspondence should be addressed to Jaclyn Hennessey Ford, Department of Psychology, Boston College, McGuinn Hall, Rm 504B, Chestnut Hill, MA 02467. E-mail: JaclynHFord@gmail.com.

DOI:10.1523/JNEUROSCI.0521-17.2017

Copyright $\odot 2017$ the authors $\quad 0270-6474 / 17 / 375172-11 \$ 15.00 / 0$
In an effort to better understand the cognitive processes supporting these changes, recent research has attempted to identify retrieval-related neural mechanisms that show variations across the adult lifespan. In these studies, one of the most frequently reported patterns is an age-related decrease in posterior occipital and parietal activity coupled with increases in prefrontal cortex (PFC) activity, a pattern known as the posterior-anterior shift in aging (PASA) (Grady et al., 1994; Davis et al., 2008). This shift has been explained as a compensatory recruitment of PFC regions due to age-related sensory-processing deficits in posterior visual regions (Davis et al., 2008). In other words, as older adults become less able to rely on posterior regions during memory tasks, they recruit the PFC more heavily to support successful retrieval.

The research described above has focused on age-related spatial shifts during the memory search phase as people assess whether they have seen information previously. However, suc- 
cessful retrieval of an event can also include a subsequent elaboration phase in which additional event details are retrieved. For example, a person may enter a restaurant and first assess whether they have been there before. After deciding that they have been there before, they may then bring to mind the details of that prior meal. Although the neural networks supporting these phases show substantial overlap, recent work suggests that they are separable networks in younger adults, with more widespread bilateral recruitment during search and preferential recruitment of medial PFC during elaboration (Ford et al., 2014a). This pattern of activity suggests that, at least in younger adults, widespread associations may be activated during the initial search phase, whereas later elaboration phases may flesh out particular episodic details.

It is currently unknown how aging may affect recruitment differentially during search and elaboration and, more specifically, whether the PASA pattern will generalize across both phases. The extant data support two competing hypotheses. First, the generalizability of the PASA pattern across cognitive domains (Grady et al., 1994, 2000, 2002; Cabeza et al., 1997, 2004; Madden and Hoffman, 1997; Madden et al., 1999, 2002; Levine et al., 2000; Rypma and D'Esposito, 2000; Anderson et al., 2000; Huettel et al., 2001; Grossman et al., 2002; Iidaka et al., 2002; Daselaar et al., 2003; Nyberg et al., 2003; Meulenbroek et al., 2004; Dennis et al., 2007) suggests that aging may be associated with decreased posterior and increased PFC recruitment across both memory phases. Such sustained age-related effects across the retrieval trial would support a general deficit in neural function in sensory-processing regions. A second alternative is that posterior regions recruited by younger adults during search will be recruited by older adults during elaboration, reflecting a change to the temporal dynamics of related processes. Such age-related shifts in the temporal dynamics of brain activity have been reported previously in the PFC (Paxton et al., 2006, 2008) and medial temporal lobe (Dew et al., 2012).

The current study uses an extended retrieval period to compare the search and elaboration phases of episodic memory retrieval in adults ages 19-85. Participants encoded emotional and neutral images presented with neutral titles. During a scanned retrieval session, participants viewed the titles and were asked to retrieve the related image. They pressed a button to indicate whether the title was "old" (studied during encoding) or "new" (not studied) and then were asked to elaborate on their memory for the remainder of the retrieval trial. This approach allows for the separation of search and elaboration processes across the adult lifespan and the use of a simple verbal cue to trigger a complex visual memory.

\section{Materials and Methods}

\section{Participants}

Data from 63 healthy adults (mean age $=47.92 \mathrm{y}, \mathrm{SD}=19.80$; mean education $=16.56 \mathrm{y}, \mathrm{SD}=2.34 ; 30$ females $)$ are reported. These participants are the same as those included in a prior study using this dataset (Ford et al., 2014b). The gender distribution did not differ as a function of age [ $43-67 \%$ male in each decade; $x^{2}(6)=0.85, p=0.99$ ] and age was not correlated with education $(p=0.68)$. Age was treated continuously for all analyses. For visualization and interpretation purposes, we looked at the participants on the extreme ends of our sample (i.e., the "youngestyounger" and the "oldest old") based on 5 approximately equivalent age groups ( $n=12,14,13,12$, and 12) that correspond to theoretically interesting age ranges: youngest-younger (ages 19-25), younger adults (age 26-39), middle-aged adults (40-54), younger old adults (55-69), and oldest old adults $(70-85)$ that have been reported in prior analyses with this dataset (Ford et al., 2014b; Ford and Kensinger, 2014).
Participants were right-handed native English speakers without psychiatric illness or neurological disorder and were recruited from the greater Boston area. All participants were paid for their participation $(\$ 20 / \mathrm{h})$ and gave written informed consent in accordance with the requirements of the Institutional Review Board at Boston College. All participants completed the Beck Anxiety Inventory (Beck et al., 1988) to examine self-reported symptoms of anxiety, as well as the Beck Depression Inventory (Beck et al., 1961) and the Geriatric Depression Scale (Sheikh and Yesavage, 1986) to evaluate symptoms of depression. In addition, participants engaged in a series of tests intended to examine general cognitive ability, vocabulary, verbal fluency, working memory, and memory (both immediate and delayed). The relations of age with all cognitive variables are reported in Table 1 . In summary, healthy aging was associated with decreased anxiety, increased vocabulary, and impairments on tasks involving long-term memory (e.g., delayed visual pairs) and executive control (e.g., digit/symbol task, mental arithmetic, mental control, digit span, and set shifting).

\section{Materials}

Stimuli were 480 pictures (160 positive, 160 negative, and 160 neutral) that were each paired with a neutral title (e.g., the neutral title "lettuce" paired with the negative image of a piece of rotting lettuce with bugs on it). These stimuli have been used in our prior studies (Ford and Kensinger, 2014, 2016; Ford et al., 2014a, 2014b) to allow presentation of a neutral cue during retrieval to elicit an emotional memory. The 480 title-picture pairs were divided into four sets of 120 pictures each (40 positive, 40 negative, and 40 neutral) for counterbalancing purposes. The length of the study list was selected to reduce the likelihood of floor or ceiling effects across the age range.

\section{Procedure}

After instruction and a short practice, participants encoded one set of 120 title-picture pairs in an intentional encoding task (outside of the scanner). Participants were given 3 s to make a decision regarding the appropriateness of each neutral title as a description of the image $(1=$ poor description, 2 = acceptable description, and $3=$ very good description).

After a half-hour delay $(\mathrm{M}=34.3 \mathrm{~min}, \mathrm{SD}=7.8)$, participants took part in a scanned retrieval task. Participants were presented with 240 neutral titles (the 120 titles that were studied during the encoding phase and 120 unstudied titles) randomly ordered across 6 retrieval runs of equal length. Participants were given up to $4 \mathrm{~s}$ to decide whether the word was "old" (i.e., seen previously) or "new" (i.e., not seen previously). The screen was removed after the participant's button press.

Immediately after an "old" response, $80 \%$ of the time, participants were asked to "elaborate" on the old item (i.e., think about the image presented with the title and the experience with that title at encoding) for $5 \mathrm{~s}$. To discourage participants from beginning to elaborate during the search phase and to distinguish activity during search from activity during elaboration, $20 \%$ of trials were catch trials; instead of an elaboration phase, the next trial was presented. After a "new" response, $80 \%$ of the time, participants moved on to the next trial. To minimize the likelihood that participants would automatically begin preparing for the next trial after a "new" response, on $20 \%$ of the trials, participants were asked to "imagine" an image that could have accompanied the new item for $5 \mathrm{~s}$.

After the elaboration/imagine phase, participants were asked to consider how well they were able to remember each item in two separate rating scales order counterbalanced across participants. Participants were given $5 \mathrm{~s}$ each for two scales: (1) on a scale of $1-5$, how well did they remember the details of the image associated with the cue word or phrase ("external vividness") and (2) on a scale of $1-5$, how well did they remember their own personal thoughts and feelings from encoding the title-picture pair ("internal vividness"). After each trial, participants viewed a fixation cross for $0-6 \mathrm{~s}$ to introduce jitter.

After being removed from the scanner, participants were represented with the same title-picture pairs from the encoding phase. They rated each image's valence and arousal on a 1-7 scale and indicated which specific emotions they experienced with each image. This portion was self-paced and participants were encouraged to respond based on their initial reaction. Researchers used this information to confirm valence assignment of the images. 
Table 1. Age-related effects on cognitive tests with averages and SD from 12 youngest and 12 oldest participants

\begin{tabular}{|c|c|c|c|c|c|}
\hline Measure & $r$ & $p$ & $\begin{array}{l}\text { Youngest participants } \\
(n=12 \text {, ages } 19-25 \mathrm{y})\end{array}$ & $\begin{array}{l}\text { Oldest participants } \\
(n=12 \text {, ages } 70-85 \mathrm{y})\end{array}$ & Reference \\
\hline Beck Anxiety Inventory & -0.33 & 0.010 & $7.25(5.64)$ & $2.17(2.66)$ & Beck et al., 1988 \\
\hline Beck Depression Index & 0.03 & 0.841 & $3(3.02)$ & $2.67(1.97)$ & Beck et al., 1961 \\
\hline Mini-Mental State Exam 2 & -0.37 & 0.003 & $29.5(0.80)$ & $28.33(1.15)$ & Folstein et al., 2010 \\
\hline Shipley Vocabulary & 0.35 & 0.005 & $33.33(3.31)$ & $37.25(3.44)$ & Shipley, 1986 \\
\hline Generative Naming & 0.11 & 0.386 & $44.25(11.27)$ & $46.33(12.56)$ & Spreen and Benton, 1977 \\
\hline Digit Symbol Substitution-90 s & -0.51 & 0.000 & $68.92(9.02)$ & $52.27(8.75)$ & \\
\hline Mental Arithmetic & -0.25 & 0.050 & $16.17(3.33)$ & $14.08(3.15)$ & \\
\hline Forward Digit Span & -0.26 & 0.040 & $12.42(2.19)$ & $10.73(2.05)$ & \\
\hline Backward Digit Span & -0.23 & 0.075 & $9.17(2.48)$ & $8.42(2.19)$ & \\
\hline \multicolumn{6}{|l|}{ Wechsler Memory Scale (Wechsler, 1997b) } \\
\hline Logical Memory-Immediate & 0.04 & 0.735 & $30.42(8.04)$ & $31.25(5.28)$ & \\
\hline Visual Pairs-Immediate & -0.22 & 0.084 & $16.75(1.29)$ & $13.92(3.75)$ & \\
\hline Visual Pairs-Delayed & -0.38 & 0.002 & $6(0.00)$ & $5.08(1.44)$ & \\
\hline Mental Control & -0.31 & 0.015 & $30.75(5.08)$ & $26(4.75)$ & \\
\hline \multicolumn{6}{|c|}{ CogState Research Battery (Maruff et al., 2009) } \\
\hline Set Shifting-Speed & 0.63 & 0.000 & $2.69(0.19)$ & $3.22(0.23)$ & \\
\hline Set Shifting-Accuracy & -0.39 & 0.002 & $84.9(6.54)$ & $74.4(9.11)$ & \\
\hline Detection-Speed & 0.38 & 0.003 & $351.1(87.15)$ & $536.33(144.60)$ & \\
\hline Detection-Accuracy & -0.17 & 0.191 & $107.18(32.81)$ & $98.16(3.87)$ & \\
\hline Identification-Speed & 0.23 & 0.076 & $465.8(85.99)$ & $645.92(111.95)$ & \\
\hline Identification-Accuracy & 0.11 & 0.394 & $95.83(4.93)$ & $95.78(4.83)$ & \\
\hline One Card Learning-Speed & 0.36 & 0.005 & $916.8(129.78)$ & $1242.17(304.74)$ & \\
\hline One Card Learning-Accuracy & -0.21 & 0.102 & $69.1(4.14)$ & $67.36(12.35)$ & \\
\hline
\end{tabular}

All values represent raw, nonstandardized means with SDs in parentheses. Significant age-related differences are bolded.

\section{Data acquisition}

Participants' heads were stabilized in a Siemens Tim Trio 3 tesla scanner. A localizing scan and auto-align scout were followed by a high-resolution multiecho T1 structural scan for anatomical visualization $(1761 \mathrm{~mm}$ slices, $\mathrm{TR}=2200 \mathrm{~ms}, \mathrm{TE} 1=1.64 \mathrm{~ms}$, TE2 $=3.5 \mathrm{~ms}$, TE3 $=5.36 \mathrm{~ms}$, TE4 $=7.22 \mathrm{~ms})$. Six runs of whole-brain, gradient-echo, echoplanar images ( $313 \mathrm{~mm}$ slices aligned along the line between the anterior and posterior commissures, $20 \%$ skip, $\mathrm{TR}=2 \mathrm{~s}, \mathrm{TE}=30 \mathrm{~ms}$, Flip angle $=90$ ) were acquired during memory retrieval using interleaved slice acquisition. A diffusion-weighted scan was collected but will not be discussed. Response data were collected using a magnet-safe button response box.

\section{Preprocessing and data analysis}

Images were preprocessed and analyzed using SPM8 software (Wellcome Department of Cognitive Neurology, London) implemented in MATLAB. Images were coregistered, realigned, normalized (resampled at $3 \mathrm{~mm}$ at the segmentation stage and written at $2 \mathrm{~mm}$ at the normalization stage), and smoothed using a Gaussian $8 \mathrm{~mm}$ kernel.

Whole-brain univariate analysis. At the subject level, the initial search phase was modeled as an event-related response at cue onset. The elaboration phase was modeled as a $5 \mathrm{~s}$ epoch beginning at the old/new button press. The fMRI analysis examined the effect of emotion (i.e., positive, negative, or neutral events) and phase (i.e., search or elaboration) on neural activity during accurate "old" responses to studied items (i.e., "hits"). Hits were modeled in six conditions: neutral search, positive search, negative search, neutral elaboration, positive elaboration, and negative elaboration. Although emotion conditions were modeled separately, emotion effects are beyond the scope of the current study and will not be discussed. Incorrect responses and correct "new" responses to unstudied items, although not relevant for the current analysis, were included in each model as two separate nuisance variables. Importantly, all search trials were included in the analysis, even those that were not followed by elaboration. Inclusion of such "catch" trials reduced the influence of collinearity between search and elaboration trials on our results.

Subject-level contrasts were examined using a full factorial ANOVA at the group level with phase (search and elaboration) and emotion (neutral, negative, and positive) as within-subject factors and age entered as a covariate of interest. Primary contrasts of interest for this analysis were the effects of age (both increasing and decreasing) on activity during search and elaboration, although effects of emotion were also examined. The significance threshold for all analyses was set at $p<0.005$ (uncorrected). Monte Carlo simulations (Slotnick et al., 2003), run with the normalized voxel size of $2 \times 2 \times 2$, determined that a 29 -voxel extent corrected results to $p<0.05$. Therefore, we discuss all clusters that reach this threshold. Clusters reaching significance were overlaid on anatomical images from MRICron. For all analyses, reported coordinates reflect the peak activity within active regions in Montreal Neurological Institute (MNI) space. These coordinates were converted from MNI coordinates to Talairach space, localized using the Talairach client, and confirmed with the Talairach and Tournoux atlas (Talairach and Tournoux, 1988).

ROI vividness analyses. ROI analyses were conducted to examine the relationship between trial-by-trial ratings of vividness and age-by-phase interactions in neural recruitment. Specifically, these analyses were conducted on regions in which age was associated with decreased recruit- 


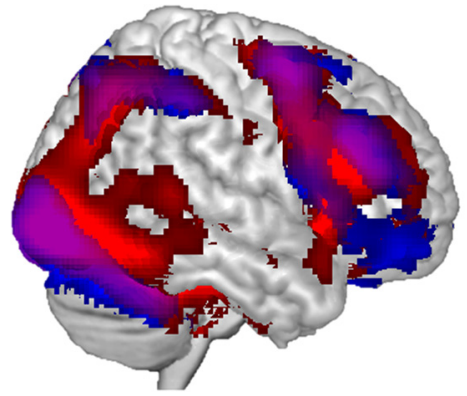

Right View

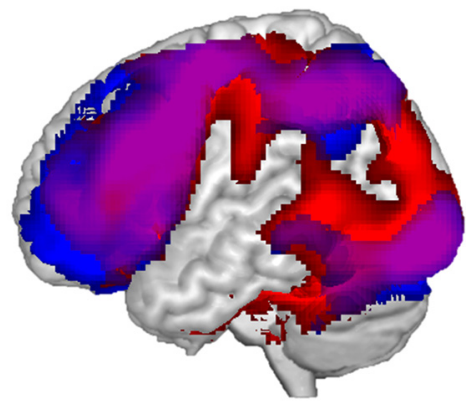

Left View

Figure 1. Neural regions recruited during the search (red regions) and elaboration (blue regions) phases of memory retrieval. Regions recruited during both search and elaboration are presented in purple. All presented regions are significant at $p<0.005$ with a 29 voxel extent.

\section{a}

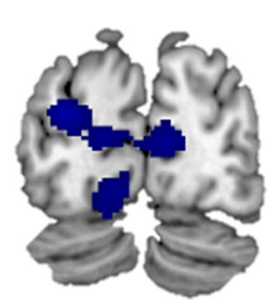

$y=-82$

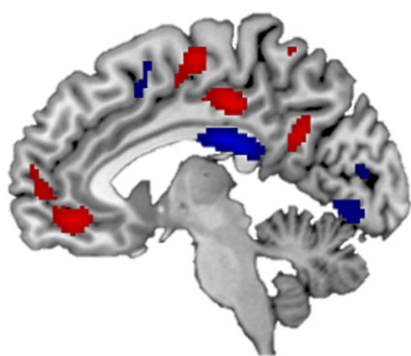

$x=-6$

b

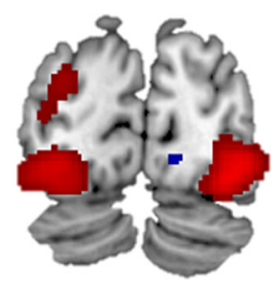

$y=-82$

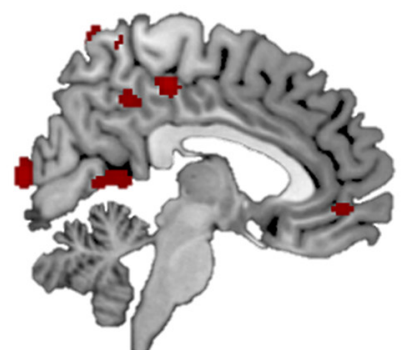

$x=4$

Figure 2. Neural regions in which recruitment was associated with age during the search $(\boldsymbol{a})$ and elaboration $(\boldsymbol{b})$ phases of memory retrieval. Regions in which age was associated with increased recruitment are presented in red and regions in which age was associated with decreased recruitment are presented in blue. All presented regions are significant at $p<0.005$ with a 29 voxel extent.

ment during search and increased recruitment during elaboration to assess whether the age-by-phase relation had any connection to the vividness of younger or older adults' memories. New fixed-effects models were generated for each subject that were identical to those described above except that two parametric modulators were added to control for trial-by-trial ratings of internal and external memory vividness. Results from these subject-level models were included in a random-effects model identical to the one described above, allowing for the examination of age-by-phase interactions within our ROIs while controlling for memory vividness. Specifically, we were able to identify clusters within each ROI in which age was associated with both a significant decrease in activity during search and an increase during elaboration.

A second set of fixed-effects models were generated to assess for any effects of vividness on neural recruitment within the ROIs. The parametric effects of vividness from these fixed-effects models, one for internal vividness and one for external vividness, were entered into an ANOVA with phase (search vs elaboration), emotion (positive, negative, and neutral), and vividness type (internal vs external) as within-subject variables

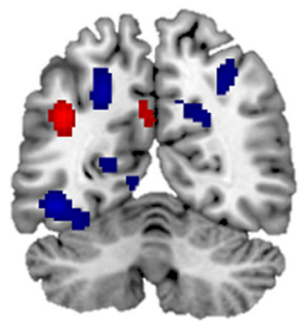

$y=-60$

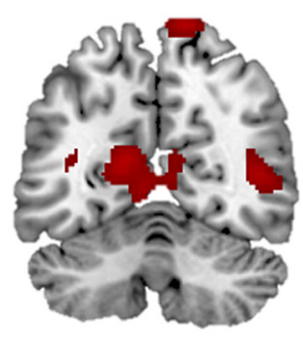

$y=-60$ of interest and age as a continuous covariate of interest. Using this model, it was possible to examine the relationship between activity in our ROIs and vividness ratings, as well as the interaction of these relations with age and phase.

Functional connectivity analyses. Finally, to examine regions exhibiting temporal reversals in age-related effects (i.e., opposite age effects during search and elaboration), the current study examined the extent to which the networks connected to these regions varied across memory phase. These analyses were conducted in an effort to determine whether these regions functioned in similar ways during search and elaboration or if they served distinct functions depending on when they were recruited during retrieval. To this end, the generalized psychophysiological interactions (gPPI; http:// brainmap.wisc.edu/PPI; McLaren et al., 2012) toolbox in SPM8 was used to examine wholebrain connectivity with regions identified in conjunction analyses that examined the overlap between negative effects of age on activity during search and positive effects of age on activity during elaboration and the overlap between positive effects of age on activity during search and negative effects of age on activity during elaboration. The gPPI toolbox, which is configured to automatically accommodate multiple task conditions in the same PPI model, compared functional connectivity to these seed regions across tasks. Volumes of interest (VOIs) were generated by creating $6 \mathrm{~mm}$ spheres around the peak voxel in all regions identified in the conjunction analyses described above. For each subject, the gPPI toolbox was used to estimate whole-brain functional connectivity with this $6 \mathrm{~mm}$ VOI during search and elaboration.

A first analysis examined spatial overlap in the networks that were functionally connected to seed regions during search and elaboration. Specifically, a conjunction analysis of functional connectivity during search and elaboration with each analysis thresholded at $p<0.05$ (FWE) was conducted to identify regions that were functionally connected to these regions regardless of memory phase. A second analysis focused on regions exhibiting significant connectivity during one phase (at $p<0.005$, with a 29-voxel extent) but not in the other phase (using an exclusive mask at $p<0.05$ ). For example, we examined regions that exhibited significant functional connectivity during search that did not overlap (even at a more lenient $p<0.05$ threshold) with regions that exhibited connectivity during elaboration. Finally, all regions exhibiting search-specific or elaboration-specific connectivity with these ROIs were further interrogated to determine whether these differences were being driven by age-related effects. Specifically, this analysis examined whether these regions overlapped with those in which connectivity was significantly related to age (at $p<0.005$, with a 29 -voxel extent).

\section{Results}

\section{Behavioral results}

Behavioral ratings were evaluated using ANOVAs with emotion (positive, negative, and neutral) as a within-subject factor and age as a covariate of interest. Participants reported an average appropriateness rating of $2.29(\mathrm{SE}=0.03)$, with no relation with age 


\begin{tabular}{|c|c|c|c|c|c|c|c|}
\hline \multirow[b]{2}{*}{ ROI } & \multirow[b]{2}{*}{ Hemisphere } & \multirow[b]{2}{*}{ BA } & \multicolumn{5}{|c|}{ MNI coordinates } \\
\hline & & & $x$ & $y$ & $z$ & $t$-value & $k$ \\
\hline \multicolumn{8}{|c|}{ Positive effect of age on neural recruitment during search } \\
\hline \multicolumn{8}{|c|}{ Frontal lobe } \\
\hline \multirow[t]{2}{*}{ Dorsal prefrontal cortex } & L & 8 & -34 & 24 & 40 & 4.36 & 551 \\
\hline & $\mathrm{R}$ & 8 & 22 & 30 & 48 & 2.97 & 42 \\
\hline Premotor cortex & L & 6 & -10 & -10 & 62 & 4.29 & 1204 \\
\hline Precentral gyrus & $\mathrm{R}$ & 4 & 28 & -14 & 58 & 3.56 & 237 \\
\hline \multirow[t]{3}{*}{ Lateral prefrontal cortex } & L & 46 & -36 & 38 & 14 & 3.50 & 89 \\
\hline & $\mathrm{R}$ & 6 & 60 & 0 & 38 & 3.24 & 70 \\
\hline & $\mathrm{R}$ & 6 & 60 & 4 & 14 & 2.99 & 64 \\
\hline Ventrolateral prefrontal cortex & L & 47 & -34 & 32 & -10 & 2.92 & 36 \\
\hline \multicolumn{8}{|l|}{ Temporal lobe } \\
\hline \multirow[t]{2}{*}{ Middle temporal gyrus } & L & 39 & -40 & -60 & 30 & 4.32 & 308 \\
\hline & L & 21 & -66 & -38 & -6 & 3.21 & 43 \\
\hline Fusiform gyrus & $\mathrm{R}$ & 20 & 60 & -30 & -34 & 3.08 & 29 \\
\hline \multicolumn{8}{|l|}{ Parietal lobe } \\
\hline Supramarginal gyrus & L & 40 & -58 & -36 & 36 & 3.22 & 58 \\
\hline Inferior parietal lobule & L & 40 & -58 & -44 & 46 & 3.16 & 66 \\
\hline & $\mathrm{R}$ & 40 & 62 & -32 & 46 & 2.84 & 53 \\
\hline Precuneus & L & 7 & -10 & -52 & 64 & 3.04 & 37 \\
\hline Postcentral gyrus & $\mathrm{R}$ & 40 & 60 & -24 & 22 & 2.89 & 52 \\
\hline Other & & & & & & & \\
\hline Anterior cingulate & $\mathrm{L}$ & 32 & 0 & 46 & -12 & 4.26 & 858 \\
\hline Posterior cingulate & L & 31 & -6 & -56 & 28 & 3.49 & 100 \\
\hline Insula & L & 13 & -58 & -34 & 18 & 3.19 & 53 \\
\hline Negative effect of age on neural recruit & & & & & & & \\
\hline Frontal lobe & & & & & & & \\
\hline Premotor cortex & L & 6 & -50 & 4 & 54 & 5.49 & 721 \\
\hline & L & 6 & 0 & 14 & 52 & 3.75 & 186 \\
\hline & L & 6 & -36 & 0 & 28 & 3.31 & 34 \\
\hline Lateral prefrontal cortex & $\mathrm{R}$ & 9 & 56 & 28 & 26 & 4.05 & 300 \\
\hline Dorsomedial prefrontal cortex & $\mathrm{R}$ & 8 & 4 & 38 & 36 & 3.50 & 65 \\
\hline Temporal lobe & & & & & & & \\
\hline Fusiform gyrus & $\mathrm{L}$ & 37 & -32 & -52 & -18 & 6.11 & 2670 \\
\hline & $\mathrm{R}$ & 20 & 38 & -42 & -20 & 3.61 & 331 \\
\hline Parietal lobe & & & & & & & \\
\hline Precuneus & $\mathrm{L}$ & 7 & -24 & -58 & 42 & 4.11 & 363 \\
\hline & $\mathrm{R}$ & 7 & 30 & -62 & 44 & 3.59 & 237 \\
\hline & L & 7 & -24 & -70 & 60 & 3.05 & 34 \\
\hline Occipital lobe & & & & & & & \\
\hline Lingual gyrus & $\mathrm{R}$ & 19 & 22 & -70 & -6 & 3.65 & 159 \\
\hline Other & & & & & & & \\
\hline Posterior cingulate & $\mathrm{L}$ & 23 & 0 & -30 & 22 & 5.54 & 598 \\
\hline & $\mathrm{R}$ & 31 & 20 & -64 & 30 & 3.52 & 235 \\
\hline Claustrum & L & NA & -30 & 24 & 0 & 3.36 & 97 \\
\hline Positive effect of age on neural recruitn & & & & & & & \\
\hline Frontal lobe & & & & & & & \\
\hline Orbitofrontal cortex & $\mathrm{L}$ & 11 & -22 & 36 & -12 & 3.50 & 61 \\
\hline Temporal lobe & & & & & & & \\
\hline Angular gyrus & L & 39 & -34 & -74 & 40 & 3.79 & 365 \\
\hline Superior temporal gyrus & L & 22 & -58 & -4 & -10 & 3.30 & 132 \\
\hline Parietal lobe & & & & & & & \\
\hline Inferior parietal lobule & L & 40 & -62 & -28 & 32 & 4.26 & 1125 \\
\hline Postcentral gyrus & $\mathrm{R}$ & 2 & 56 & -20 & 28 & 3.70 & 461 \\
\hline & L & 2 & -36 & -32 & 72 & 3.29 & 71 \\
\hline & L & 7 & -20 & -46 & 58 & 3.18 & 117 \\
\hline Precuneus & $\mathrm{R}$ & 7 & 12 & -60 & 74 & 3.68 & 985 \\
\hline Occipital lobe & & & & & & & \\
\hline Fusiform gyrus & $\mathrm{R}$ & 19 & 34 & -84 & -10 & 5.27 & 2141 \\
\hline & $\mathrm{R}$ & 19 & 22 & -48 & 2 & 3.17 & 156 \\
\hline & L & 19 & -36 & -64 & 14 & 2.97 & 55 \\
\hline Middle occipital gyrus & L & 18 & -32 & -88 & -6 & 5.15 & 1462 \\
\hline Lingual gyrus & L & 17 & 2 & -94 & 8 & 3.42 & 67 \\
\hline Other & & & & & & & \\
\hline Posterior cingulate & $\mathrm{L}$ & 30 & -14 & -58 & 12 & 3.87 & 885 \\
\hline & L & 31 & -12 & -32 & 48 & 3.76 & 288 \\
\hline & $\mathrm{R}$ & 31 & 4 & -46 & 42 & 2.99 & 61 \\
\hline Anterior cingulate & R & 32 & 2 & 48 & -6 & 3.02 & 43 \\
\hline
\end{tabular}


Table 2. Continued

\begin{tabular}{|c|c|c|c|c|c|c|c|}
\hline \multirow[b]{2}{*}{ ROI } & \multirow[b]{2}{*}{ Hemisphere } & \multirow[b]{2}{*}{ BA } & \multicolumn{5}{|c|}{ MNI coordinates } \\
\hline & & & $x$ & $y$ & $z$ & $t$-value & k \\
\hline \multicolumn{8}{|c|}{$\begin{array}{l}\text { Positive effect of age on neural recruitment during elaboration } \\
\text { Frontal lobe }\end{array}$} \\
\hline \multirow{2}{*}{ Premotor cortex } & L & 6 & -28 & 6 & 66 & 3.51 & 78 \\
\hline & $\mathrm{R}$ & 6 & 16 & 4 & 66 & 3.13 & 61 \\
\hline Lateral prefrontal cortex & L & 9 & -58 & 14 & 26 & 3.02 & 32 \\
\hline
\end{tabular}

Clusters significant at an uncorrected threshold of $p<0.005, k \geq 29$ voxels.

BA, Approximate Brodmann area.

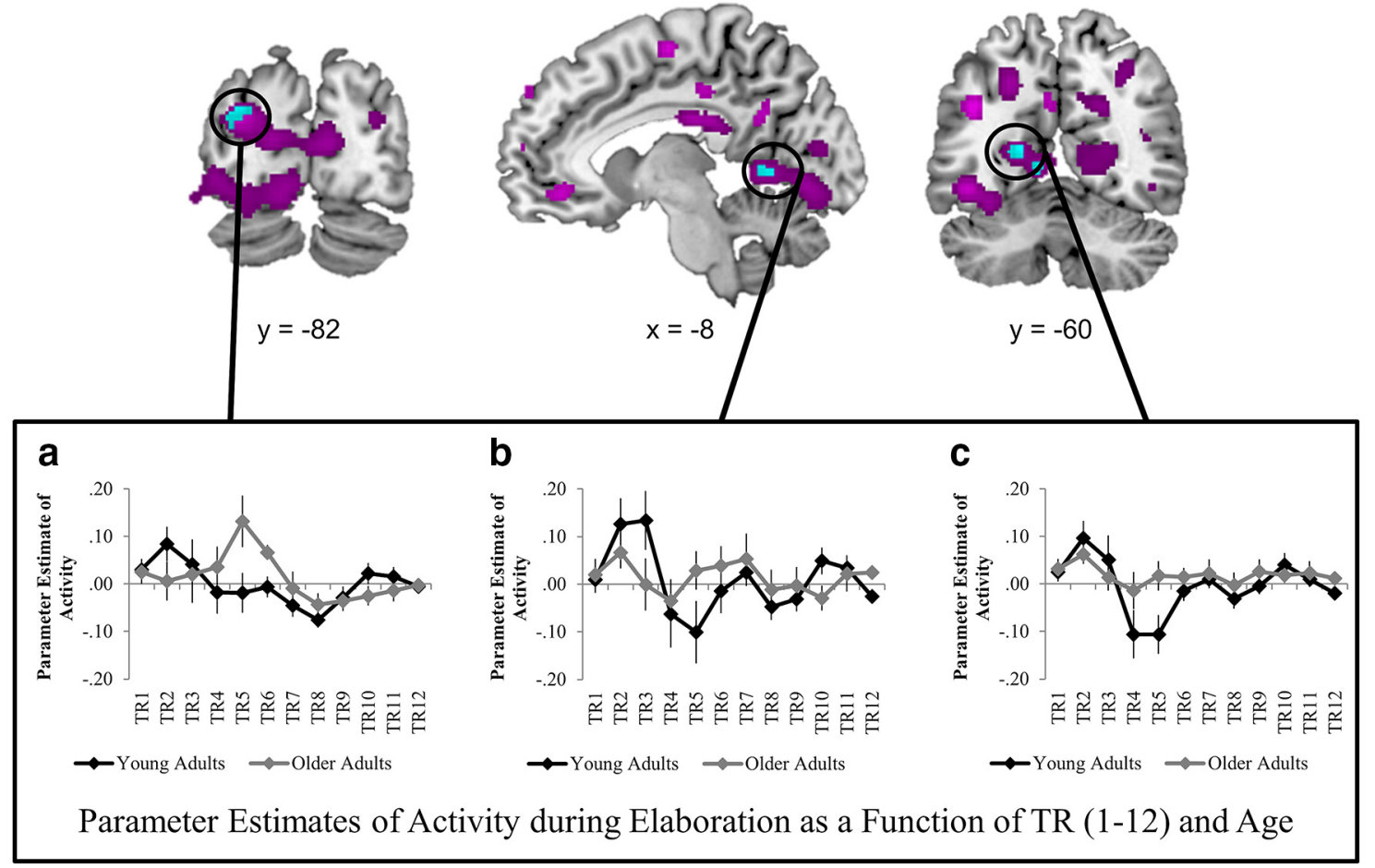

Figure 3. Regions in which the effects of age on neural recruitment differed significantly as a function of memory phase (i.e., age-by-phase interaction) at $p<0.005$ with a 29 voxel extent are presented in purple. Regions in which age is associated with both significant decreases in recruitment during search and significant increases in recruitment during elaboration (i.e., a conjunction of $p<0.005$ with a 29 voxel extent for both contrasts) are presented in cyan. The elaboration time course of these three R0ls $(\boldsymbol{a}:-32,-82,26 ; \boldsymbol{b}$ : $-8,-60,0 ; \boldsymbol{c}:-18,-60,10)$ are presented for the 12 youngest and 12 oldest adults in the sample.

$\left(F_{(1,61)}=0.09, p=0.77, \eta_{\mathrm{p}}^{2}=0.00\right)$. Age was associated with significant decreases in hit rate $\left(\mathrm{M}=0.70, \mathrm{SE}=0.01 ; F_{(1,61)}=\right.$ $\left.11.75, p=0.001, \eta_{\mathrm{p}}^{2}=0.16\right)$, but no changes to false alarms $(\mathrm{M}=$ $\left.0.11, \mathrm{SE}=0.01 ; F_{(1,61)}=2.75, p=0.10, \eta_{\mathrm{p}}^{2}=0.04\right)$. Age was also associated with increases in retrieval times $(\mathrm{M}=1821.19, \mathrm{SE}=$ 41.66; $\left.F_{(1,61)}=9.23, p=0.004, \eta_{\mathrm{p}}^{2}=0.13\right)$.

Vividness was evaluated using and ANOVA with emotion (positive, negative, and neutral) and vividness type (external vs internal) as within-subject factors and age as a covariate of interest. Participants provided higher external $(\mathrm{M}=3.60, \mathrm{SE}=$ $0.08)$ than internal vividness ratings $\left(\mathrm{M}=3.11, \mathrm{SE}=0.08 ; F_{(1,57)}=\right.$ $\left.10.62, p=0.002, \eta_{\mathrm{p}}^{2}=0.16\right)$, with no effect of age $\left(F_{(1,57)}=0.04\right.$, $\left.p=0.85, \eta_{\mathrm{p}}^{2}=0.001\right)$ or an age-by-vividness type interaction $\left(F_{(1,57)}=1.19, p=0.28, \eta_{\mathrm{p}}^{2}=0.02\right)$.

Whereas there were no age-by-emotion interactions for appropriateness, hit rate, or reaction time (RT), there was a significant age-by-emotion interaction on vividness ratings: whereas vividness ratings in younger adults were numerically greatest for negative events $(\mathrm{M}=3.57, \mathrm{SE}=0.18)$, followed by positive events $(M=3.47, S E=0.16)$, then neutral events $(M=3.13$, $\mathrm{SE}=0.17)$ in older adults, vividness ratings for positive events $(\mathrm{M}=3.63, \mathrm{SE}=0.19)$ were significantly greater than those for negative events $(\mathrm{M}=3.37, \mathrm{SE}=0.18 ; p=0.024)$ and neutral events $(\mathrm{M}=3.32, \mathrm{SE}=0.16 ; p=0.001)$.

\section{Imaging results}

Neural recruitment during memory search and elaboration A complete investigation of the effects of phase on neural recruitment was conducted previously on a younger adult subset of the current sample (Ford et al., 2014a). The results with the larger age range analyzed here were generally consistent with that prior analysis: search and elaboration were both associated with recruitment of a widespread neural network including frontal, parietal, and occipital regions (Fig. 1), with activation associated with search extending to cover additional parietal, occipital, and 
medial temporal lobe regions. Elaboration was associated with more extensive recruitment of prefrontal regions.

Effects of age on neural recruitment during memory search During memory search, age was associated with increased recruitment of dorsal (BA8), lateral (BA6 and BA46), and ventrolateral prefrontal regions (BA47), as well as anterior cingulate (BA32) that extended into ventromedial PFC (Fig. $2 a$, red regions, Table 2). Increased age was also associated with increased recruitment in the middle temporal gyrus (BA21 and BA39), fusiform gyrus (BA20), parietal lobe (BA40), precuneus (BA7), posterior cingulate (BA31), and insula (BA13). The reverse contrast, identifying regions preferentially recruited by younger relative to older adults, revealed that increased age was associated with decreased recruitment in a number of posterior regions such as fusiform gyrus (BA37 and BA20), precuneus (BA7), lingual gyrus (BA19), and posterior cingulate (BA23 and BA31), as well as lateral (BA9) and dorsomedial PFC (BA8; Fig. 2a, blue regions, Table 2).

Effects of age on neural recruitment during memory elaboration Age was associated with increased recruitment of posterior regions such as fusiform gyrus (BA19), middle occipital gyrus (BA18), lingual gyrus (BA17), posterior cingulate (BA30 and BA31), parietal lobe (BA40), and precuneus (BA7), as well as orbitofrontal cortex (BA11) and lateral temporal regions (BA39 and BA22) (Fig. 2b, red regions, Table 2). Increased age was also associated with decreased activity in the lingual gyrus (BA18), lateral PFC (BA9), and three clusters of the premotor cortex (BA6) (Fig. 2b, blue regions, Table 2).

Age-by-phase interactions during memory retrieval

As would be predicted based on the results reported above, ageby-phase interactions in neural recruitment were identified in number of prefrontal regions such as dorsal PFC (BA8 and BA9), anterior PFC (BA10), lateral PFC (BA9 and BA46), ventrolateral PFC (BA 47 and BA11), and dorsomedial PFC (BA8), as well as posterior visual regions such as middle occipital gyrus (BA19), posterior cingulate (BA30), fusiform gyrus (BA37 and BA19), precuneus (BA7), and cuneus (BA19), suggesting that age was differentially related to neural recruitment in these regions during search versus elaboration (Fig. 3, purple regions, Table 3). Conjunction analyses revealed that three clusters, the middle occipital gyrus (BA19), fusiform gyrus (BA19), and posterior cingulate (BA30) (Fig. 3, cyan regions), actually exhibited a complete temporal reversal in age effects from search to elaboration. In these regions, there was a significant negative effect of age during search (i.e., decreased recruitment as a function of age) and a significant positive effect of age during elaboration (i.e., increased recruited as a function of age). No regions were identified in the opposite conjunction (i.e., a significant positive effect of age during search and a negative effect of age during elaboration). Critically, there were no interactions with emotion or valence in any of the three clusters identified in the conjunction analysis, suggesting that the temporal age reversal in these regions occurred regardless of emotional content.

To determine whether the age-by-phase interactions were driven by age differences in hit rate or RT, ANOVAs were conducted on all three ROIs with emotion (neutral, positive, and negative) and phase (search and elaboration) as between-subject factors and age and either hit rate or RT as between-subject factors. Hit-by-phase interactions and RT-by-phase interactions were insignificant for all three ROIs $(p>0.1$ for all comparisons), suggesting that these behavioral differences may not be
Table 3. Age-by-phase interactions in neural recruitment during memory retrieval

\begin{tabular}{|c|c|c|c|c|c|c|c|}
\hline \multirow[b]{2}{*}{ ROI } & \multirow[b]{2}{*}{ Hemisphere } & \multirow[b]{2}{*}{ BA } & \multicolumn{5}{|c|}{ MNI coordinates } \\
\hline & & & $x$ & $y$ & $z$ & $t$-value & $k$ \\
\hline \multicolumn{8}{|l|}{ Frontal lobe } \\
\hline \multirow[t]{6}{*}{ Premotor cortex } & $\mathrm{L}$ & 6 & -52 & 4 & 56 & 4.50 & 786 \\
\hline & $\mathrm{L}$ & 6 & -8 & -10 & 60 & 3.60 & 72 \\
\hline & $\mathrm{L}$ & 6 & -36 & 0 & 28 & 3.43 & 52 \\
\hline & $\mathrm{L}$ & 6 & 0 & 14 & 52 & 3.04 & 51 \\
\hline & $\mathrm{L}$ & 6 & -24 & 14 & 68 & 3.06 & 40 \\
\hline & $\mathrm{R}$ & 6 & 28 & -12 & 56 & 2.94 & 38 \\
\hline \multirow[t]{3}{*}{ Dorsal prefrontal cortex } & $\mathrm{L}$ & 8 & -34 & 24 & 40 & 4.33 & 467 \\
\hline & $\mathrm{L}$ & 9 & -24 & 42 & 44 & 3.13 & 58 \\
\hline & L & 9 & -6 & 58 & 38 & 2.92 & 32 \\
\hline \multirow[t]{2}{*}{ Lateral prefrontal cortex } & $\mathrm{R}$ & 9 & 56 & 28 & 26 & 4.00 & 224 \\
\hline & L & 46 & -36 & 38 & 14 & 3.51 & 114 \\
\hline Dorsomedial prefrontal cortex & $\mathrm{R}$ & 8 & 6 & 38 & 36 & 3.67 & 65 \\
\hline Precentral gyrus & $\mathrm{L}$ & 4 & -24 & -16 & 66 & 3.66 & 148 \\
\hline Anterior prefrontal cortex & $\mathrm{L}$ & 10 & -14 & 54 & 16 & 3.66 & 182 \\
\hline \multirow[t]{2}{*}{ Ventrolateral prefrontal cortex } & $\mathrm{L}$ & 47 & -54 & 22 & -10 & 3.01 & 30 \\
\hline & $\mathrm{L}$ & 11 & -2 & 44 & -12 & 3.82 & 270 \\
\hline \multicolumn{8}{|l|}{ Temporal lobe } \\
\hline Fusiform gyrus & $\mathrm{L}$ & 37 & -32 & -52 & -18 & 6.16 & 5858 \\
\hline \multirow[t]{3}{*}{ Middle temporal gyrus } & $\mathrm{L}$ & 39 & -40 & -60 & 30 & 3.81 & 161 \\
\hline & L & 21 & -66 & -38 & -6 & 3.04 & 30 \\
\hline & $\mathrm{R}$ & 39 & 40 & -56 & 16 & 2.99 & 44 \\
\hline Superior temporal gyrus & $\mathrm{R}$ & 22 & 52 & -40 & 4 & 2.88 & 31 \\
\hline \multicolumn{8}{|l|}{ Parietal lobe } \\
\hline \multirow[t]{2}{*}{ Precuneus } & L & 7 & -24 & -58 & 42 & 4.09 & 371 \\
\hline & $\mathrm{R}$ & 7 & 30 & -64 & 42 & 3.61 & 302 \\
\hline Inferior parietal lobule & L & 40 & -56 & -46 & 46 & 3.42 & 110 \\
\hline \multicolumn{8}{|l|}{ Occipital lobe } \\
\hline \multirow[t]{2}{*}{ Fusiform gyrus } & $\mathrm{R}$ & 19 & 42 & -70 & -8 & 4.01 & 615 \\
\hline & L & 19 & -8 & -60 & 0 & 3.16 & 36 \\
\hline Middle occipital gyrus & L & 19 & -32 & -82 & 26 & 3.23 & 57 \\
\hline Cuneus & $\mathrm{R}$ & 19 & 30 & -80 & 20 & 3.17 & 74 \\
\hline \multicolumn{8}{|l|}{ Other } \\
\hline \multirow[t]{2}{*}{ Posterior cingulate } & $\mathrm{R}$ & 23 & 6 & -30 & 24 & 5.23 & 518 \\
\hline & L & 30 & -18 & -60 & 10 & 3.50 & 72 \\
\hline \multirow[t]{2}{*}{ Insula } & L & 13 & -30 & 24 & 0 & 3.81 & 129 \\
\hline & $\mathrm{R}$ & 13 & 32 & 30 & 2 & 3.16 & 42 \\
\hline Anterior cingulate & L & 24 & -2 & -20 & 46 & 3.43 & 257 \\
\hline Posterior cingulate & L & 31 & -6 & -56 & 28 & 3.35 & 77 \\
\hline
\end{tabular}

Bolded coordinates reflect regions associated with a significant negative effect of age during search and a significant positive effect of age during elaboration at $p<0.005, k \geq 29$ voxels for both contrasts. Clusters significant at an uncorrected threshold of $p<0.005, k \geq 29$ voxels.

$B A$, Approximate Brodmann area.

responsible for age effects. Further, the critical age-by-phase interactions remained significant in all analyses except one: when hit rate was included in the ANOVA examining activity in the middle occipital gyrus, the significant age-by-phase interaction was reduced to a trending effect of $p=0.07$.

\section{Vividness analyses in regions showing temporal reversals in} age-related effects on neural recruitment

Conjunction analyses revealed that age was associated with both decreased recruitment during search and increased recruitment during elaboration in all three ROIs, the middle occipital gyrus (BA19; peak $p=0.002, k=21$ ), fusiform gyrus (BA19; peak $p=$ $0.003, k=13$ ), and posterior cingulate (BA30; peak $p<0.001$, $k=67$ ), when controlling for vividness ratings. Vividness ratings were related to activity in all three ROIs, the middle occipital gyrus (BA19; peak $p=0.002, k=90$ ), fusiform gyrus (BA19; peak $p=0.003, k=4)$, and posterior cingulate (BA30; peak $p<0.001$, $k=28$ ). The relation with vividness within these ROIs did not differ as a function of phase, age, or the age-by-phase interaction (no significant voxels reaching $p<0.005$ ). Therefore, it is un- 
Table 4. Regions exhibiting connectivity with three posterior regions identified in the conjunction analysis $(-18,-60,-10 ;-32,-82,26 ;-8,-60,0)$ during search and elaboration

\begin{tabular}{|c|c|c|c|c|c|c|c|c|c|c|c|c|c|c|c|c|c|c|c|c|c|}
\hline \multirow[b]{3}{*}{ ROI } & \multicolumn{7}{|c|}{ Posterior cingulate $(-18,-60,10)$} & \multicolumn{7}{|c|}{ Middle occipital gyrus $(-32,-82,26)$} & \multicolumn{7}{|c|}{ Fusiform gyrus $(-8,-60,0)$} \\
\hline & \multirow[b]{2}{*}{ Hem } & \multirow[b]{2}{*}{ BA } & \multicolumn{3}{|c|}{ MNI coordinates } & \multirow[b]{2}{*}{$t$-value } & \multirow[b]{2}{*}{$k$} & \multirow[b]{2}{*}{ Hem } & \multirow[b]{2}{*}{ BA } & \multicolumn{3}{|c|}{ MNI coordinates } & \multirow[b]{2}{*}{$t$-value } & \multirow[b]{2}{*}{$k$} & \multirow[b]{2}{*}{ Hem } & \multirow[b]{2}{*}{$B A$} & \multicolumn{3}{|c|}{ MNI coordinates } & & \\
\hline & & & $x$ & $y$ & $z$ & & & & & $x$ & $y$ & $z$ & & & & & $x$ & $y$ & $z$ & $t$-value & $k$ \\
\hline Regions exhibiting significant connect & ivity di & Iring se & search ( & $p<0$ & $005, k \geq$ & $\geq 29$ voxe & as) but r & not elal & orati & on $(p<$ & $0.05)$ & & & & & & & & & & \\
\hline Frontal lobe & & & & & & & & & & & & & & & & & & & & & \\
\hline Dorsal prefrontal cortex & $\mathrm{R}$ & 9 & 20 & 44 & 34 & 4.62 & 155 & $\mathrm{R}$ & 8 & 14 & 42 & 42 & 4.11 & 44 & & & & & & & \\
\hline Ventromedial prefrontal cortex & R & 25 & 6 & 20 & -8 & 4.42 & 177 & $\mathrm{R}$ & 11 & 2 & 52 & -18 & 4.18 & 95 & L & 25 & 2 & 14 & -10 & 3.41 & 32 \\
\hline & & & & & & & & $\mathrm{L}$ & 10 & -14 & 58 & 12 & 5.03 & 410 & $\mathrm{R}$ & 10 & 16 & 54 & 20 & 4.14 & 37 \\
\hline Medial prefrontal cortex & & & & & & & & & & & & & & & R & 10 & 18 & 48 & -2 & 3.32 & 51 \\
\hline Temporal lobe & & & & & & & & & & & & & & & & & & & & & \\
\hline Middle temporal gyrus & & & & & & & & L & 21 & -42 & -12 & -16 & 4.75 & 757 & L & 21 & -42 & -10 & -16 & 5.18 & 142 \\
\hline Superior temporal gyrus & & & & & & & & $\mathrm{R}$ & 22 & 46 & -16 & -2 & 4.5 & 435 & R & 38 & 40 & 4 & -18 & 3.95 & 106 \\
\hline Occipital lobe & & & & & & & & & & & & & & & & & & & & & \\
\hline Lingual gyrus & & & & & & & & $\mathrm{R}$ & 18 & 22 & -92 & -8 & 3.95 & 49 & $\mathrm{R}$ & 18 & 24 & -90 & -4 & 4.8 & 64 \\
\hline & & & & & & & & L & 18 & -16 & -88 & -12 & 3.82 & 44 & & & & & & & \\
\hline Other & & & & & & & & & & & & & & & & & & & & & \\
\hline Amygdala & $\mathrm{R}$ & NA & 26 & 4 & -24 & 3.23 & 45 & $\mathrm{R}$ & NA & 24 & -8 & -14 & 4.48 & 139 & $\mathrm{R}$ & 34 & 20 & -2 & -24 & 3.81 & 54 \\
\hline Anterior cingulate & & & & & & & & $\mathrm{R}$ & 32 & 16 & 42 & 2 & 4.59 & 717 & & & & & & & \\
\hline & & & & & & & & $R$ & 24 & 6 & 22 & -6 & 3.47 & 42 & & & & & & & \\
\hline Hippocampus & & & & & & & & L & NA & -32 & -24 & -12 & 4.49 & 48 & & & & & & & \\
\hline Caudate & & & & & & & & L & NA & -10 & 24 & -4 & 4.03 & 79 & & & & & & & \\
\hline Parahippocampal gyrus & & & & & & & & & & & & & & & $\mathrm{L}$ & 36 & -16 & -12 & -24 & 3.9 & 75 \\
\hline Insula & & & & & & & & & & & & & & & $\mathrm{R}$ & 13 & 50 & -2 & -2 & 3.69 & 31 \\
\hline Cerebellum & & & & & & & & & & & & & & & $\mathrm{L}$ & NA & -8 & -44 & -18 & 3.51 & 43 \\
\hline Regions exhibiting significant connecti & ivity d & uring $\mathrm{e}$ & elaborat & $\operatorname{tion}(p$ & $<0.00$ & $5, k \geq 29$ & voxels) & ) but no & t sear & $\operatorname{ch}(p<$ & $0.05)$ & & & & & & & & & & \\
\hline Temporal lobe & & & & & & & & & & & & & & & & & & & & & \\
\hline Inferior temporal gyrus & L & 20 & -42 & 0 & -36 & 3.35 & 30 & & & & & & & & & & & & & & \\
\hline Occipital lobe & & & & & & & & & & & & & & & & & & & & & \\
\hline Lingual gyrus & L & 18 & -28 & -80 & 2 & 5 & 77 & & & & & & & & & & & & & & \\
\hline & L & 18 & -24 & -56 & 0 & 3.91 & 32 & & & & & & & & & & & & & & \\
\hline & $\mathrm{R}$ & 19 & 36 & -70 & 4 & 4.93 & 115 & & & & & & & & & & & & & & \\
\hline Other & & & & & & & & & & & & & & & & & & & & & \\
\hline Parahippocampal gyrus & $\mathrm{R}$ & 36 & 22 & -22 & -26 & 3.38 & 92 & & & & & & & & & & & & & & \\
\hline Thalamus & L & NA & -4 & -6 & 4 & 4.18 & 45 & $\mathrm{~L}$ & NA & -2 & -20 & 14 & 3.76 & 70 & & & & & & & \\
\hline Caudate & & & & & & & & & & & & & & & $\mathrm{R}$ & NA & 16 & -2 & 24 & 3.95 & 86 \\
\hline Posterior cingulate & & & & & & & & & & & & & & & $\mathrm{R}$ & 23 & 14 & -40 & 22 & 3.87 & 49 \\
\hline Anterior cingulate & & & & & & & & & & & & & & & L & 24 & -10 & -2 & 30 & 3.81 & 137 \\
\hline & & & & & & & & & & & & & & & $\mathrm{R}$ & 24 & 10 & 18 & 20 & 3.54 & 41 \\
\hline Cerebellum & $\mathrm{L}$ & NA & -46 & -52 & -28 & 5.22 & 33 & $\mathrm{~L}$ & NA & -14 & -48 & -42 & 3.95 & 76 & $\mathrm{~L}$ & NA & -20 & -34 & -36 & 4.05 & 63 \\
\hline & L & NA & -18 & -32 & -36 & 4.6 & 370 & & & & & & & & & & & & & & \\
\hline & $\mathrm{R}$ & NA & 4 & -70 & -12 & 5.18 & 1670 & $\mathrm{R}$ & NA & 6 & -68 & -10 & 3.86 & 51 & & & & & & & \\
\hline & $\mathrm{R}$ & NA & 20 & -50 & -40 & 4.76 & 251 & $\mathrm{R}$ & NA & 18 & -42 & -42 & 3.71 & 178 & & & & & & & \\
\hline
\end{tabular}

Hem, Hemisphere; BA, approximate Brodmann area; NA, not applicable.

likely that age differences in memory vividness were driving the reported age-by-phase interactions in posterior regions.

Whole-brain functional connectivity with regions showing temporal reversals in age-related effects on neural recruitment Whole-brain functional connectivity during search and elaboration was examined using the three clusters identified in the conjunction analysis described above, the middle occipital gyrus (BA19), fusiform gyrus (BA19), and posterior cingulate (BA30) (Fig. 3, cyan regions), as seed regions. All three seed regions exhibited significant connectivity with a number of prefrontal regions, including dorsal PFC (BA9 and BA8), ventromedial PFC (BA25, BA11, and BA 10), and medial PFC (BA10), during search but not during elaboration (Table 4). Connectivity between these seed regions and medial temporal lobe regions such as right amygdala and left hippocampus was also specific to the search phase of retrieval. Elaboration-specific connectivity was not as reliable across seed regions, with the greatest consistency in the cerebellum. The posterior cingulate also exhibited elaboration-specific connectivity in posterior regions such as the lingual gyrus (BA18 and BA19) and parahippocampal gyrus (BA36), whereas the fusiform gyrus exhibited elaboration-specific connectivity in the caudate as well as the posterior (BA23) and anterior (BA24) cingulate. Critically, none of the regions exhibiting search-specific or elaborationspecific connectivity was related to age.

Despite these phase-specific patterns, all three regions exhibited widespread whole-brain connectivity during both search and elaboration, revealing substantial overlap across phases. Indeed, a conjunction analysis of connectivity during search and elaboration with a more conservative threshold (FWE, $p<0.05$ for both contrasts) revealed that these posterior regions were functionally connected to bilateral medial and lateral frontal, parietal, temporal, and occipital regions, with the greatest connectivity in posterior occipital and lateral temporal lobes (Fig. 4). In other words, although search and elaboration connectivity patterns exhibited some distinctions, their commonalities were far more extensive and suggest overwhelming similarities in how these regions function across phases. 


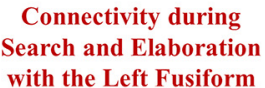
with the Left Fusiform Gyrus $(-8,-60,0)$

Connectivity during Search and Elaboration with the Left Posterior Cingulate $(-18,-60,10)$
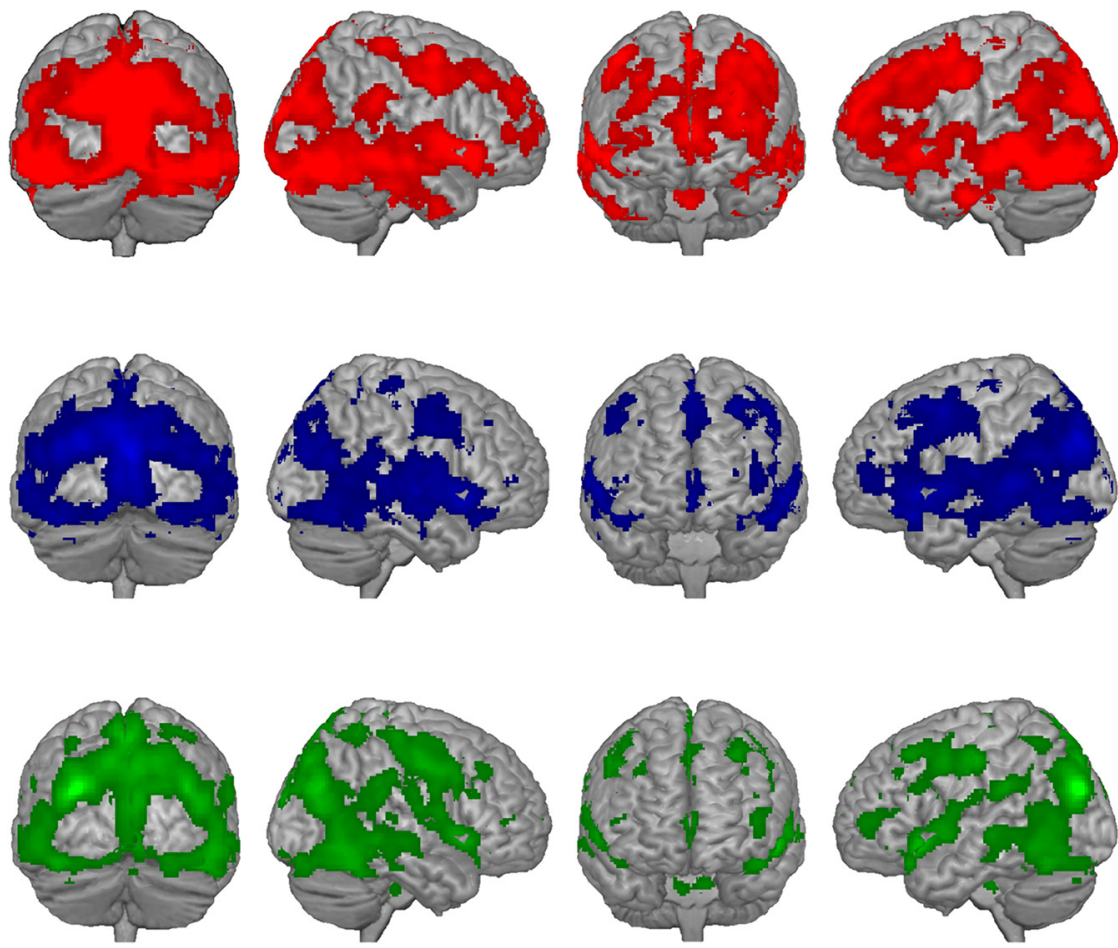

Figure 4. Neural regions exhibiting significant functional connectivity with the left fusiform gyrus (red), left posterior cingulate (blue), or left middle occipital gyrus (green) during both search and elaboration.

\section{Discussion}

The current study was the first to examine how the well documented posterior-anterior shift in aging may be eliminated during elongated task trials. Specifically, age-related effects in posterior recruitment exhibited a temporal reversal during retrieval, in which younger adults recruited these regions more than older adults during an initial search phase and older adults recruited these regions more than younger adults during a subsequent elaboration phase. Evidence from ROI and functional connectivity analyses suggests that these posterior regions function in comparable ways in search and elaboration, contributing to overall memory vividness ratings and interacting with similar neural networks. Critically, these findings suggest that the posterior-anterior shift does not reflect an overall failure of older adults to engage posterior regions during cognitive tasks, but rather a delay in engagement that has not been captured by prior designs. Dew et al. (2012) proposed that this effect, called the "early-to-late shift in aging" (ELSA), may be a generalized feature of aging rather than a specific effect of a particular region or cognitive task. In other words, depending on the particular demands of a cognitive task, ELSA may be seen in different neural regions and may help to explain a number of age differences currently reported in the cognitive neuroscience literature.

In the current task, participants were asked to engage in an initial search phase in which they accessed the memory trace and a subsequent elaboration phase in which they retrieved additional event details. During search, age was associated with increased recruitment of regions within the PFC and decreased recruitment of more posterior sensory regions. These findings were consistent with prior findings of a PASA (Davis et al., 2008). Critically, by using a protracted retrieval trial consisting of both a search and elaboration phase, the current study was able to demonstrate that this PASA effect was limited to the initial search phase and did not extend to elaboration. In fact, activity in three posterior sensory regions exhibited the opposite effect of age in the elaboration time period, when age was associated with increased recruitment. In other words, although older adults may rely on prefrontal regions to compensate for a lack of posterior recruitment during search, they are able to recruit these same posterior regions later in the retrieval trial if given the opportunity for elaboration.

Follow-up analyses revealed that these three ROIs were related to enhanced vividness ratings regardless of memory phase or participants age. In addition, they exhibited widespread and overlapping whole-brain connectivity during both search and elaboration. Critically, the extensive overlap in connectivity across the two retrieval phases suggests that these regions were associated with similar neural networks regardless of when during retrieval they were recruited. These findings may reflect the ability of older adults to engage in similar processes during elaboration as younger adults do during search. In other words, the initial age-related decrease in posterior recruitment may reflect a delayed implementation of processing in occipital regions during retrieval rather than a global deficit in such processing.

Prior behavioral studies have demonstrated that younger and older adults often focus on different types of details during memory retrieval, with younger adults more likely to report perceptual details and older adults more likely to report personal thoughts and feelings related to the event (Hashtroudi et al., 1990; Comblain et al., 2004; Schaefer and Philippot, 2005). These distinct detail types were evaluated in the current study using measures of internal and external vividness and exhibited no age effects. One possibility for this null result is that the inclusion of an elaboration period, as well as the explicit instruction to think about and rate both internal and external details, allowed older adults the opportunity to recruit processes typically engaged by younger adults during search. In other words, the age-related differences in detail focus in memory studies may reflect shifts in how 
younger and older adults initially access event details and in the information that they tend to focus on in a natural setting. However, when asked explicitly to consider both internal and external details and when given the time to do so, behavioral age differences may be minimal. Although this explanation is consistent with our neuroimaging data, it is based on an interpretation of a null behavioral finding. Therefore, additional work is still needed to evaluate the relation between this temporal reversal and behavioral retrieval of memory detail.

The current study suggests that age is associated with changes to the temporal dynamics of posterior visual recruitment rather than an inability of older adults to recruit these regions during memory retrieval. As with many cognitive aging studies, it can be important to consider how differences in performance may influence effects of age on neural recruitment. The results of the current study suggest that behavioral changes were not the primary cause of age-related neural effects. Further, if the temporal reversal were simply a product of the well documented cognitive slowing in aging (Salthouse, 1996), then one would expect to see the age-related enhancement during elaboration for all regions in which there was an age-related decrease in recruitment during search. This was not the case and, in fact, there were several regions exhibiting age-related decreases in recruitment during both phases. Finally, Dew et al. (2012) revealed that their ELSA effect in the medial temporal lobe was inversely related to RT in both younger and older adults, the opposite of what would be predicted by cognitive slowing. However, because RT and hit rate may be tightly linked to the sorts of retrieval strategies used by younger and older adults, future work is needed to disentangle these effects more fully.

In addition, it is important to consider the fact that age can not only influence the neural signal contributing to the fMRI BOLD measures, but can also be associated with significant vascular changes that alter the BOLD signal and can exaggerate age-related effects (D'Esposito et al., 2003; Hutchinson et al., 2013, 2013). Indeed, by controlling for such vascular changes in the BOLD signal, a recent study eliminated age-related decreases in posterior recruitment during a sensorimotor task (Tsvetanov et al., 2015). These physiological changes may also contribute to a delayed rise time of the hemodynamic response in older adults (Taoka et al., 1998). However, there is evidence suggesting that delays in rise time may not exist in visual regions (Huettel et al., 2001) and no evidence suggesting a specific slowing in posterior visual regions, as would be required to produce the effects presented in the current study.

Finally, it is important in studies of cognitive aging to consider potential selection biases in our sample. The older adults in our sample were highly educated individuals who had been screened for potential health problems and dementia. In addition, they were older adults who are interested in research and motivated to come to the MR scanner for a $3 \mathrm{~h}$ session. In the current study, we must also consider the generalizability of the middle-aged adults because it is often difficult for individuals in this age range to take the time to come into laboratories for study sessions. Therefore, it is possible that the reported effects of age reflect a particular subsample.

The current study demonstrated, for the first time, that the posterior-anterior shift in aging that is commonly reported in cognitive tasks (Davis et al., 2008) may be limited to the initial search phase of memory retrieval. Importantly, three posterior regions showing age-related decreases in recruitment during search showed significant age-related increases during elaboration, suggesting that older adults can rely on similar regions dur- ing elaboration as younger adults do during search. Further, follow-up connectivity analyses suggested that these posterior regions may function at least partially in a similar fashion regardless of memory phase. Together, these results suggest that reported age-related decreases in posterior recruitment in cognitive tasks do not reflect global sensory-processing deficits, but rather that older adults may be capable of engaging similar retrieval processes as younger adults if given sufficient processing time.

\section{References}

Anderson ND, Iidaka T, Cabeza R, Kapur S, McIntosh AR, Craik FI (2000) The effects of divided attention on encoding- and retrieval-related brain activity: a PET study of younger and older adults. J Cogn Neurosci 12: 775-792. CrossRef Medline

Beck AT, Ward CH, Mendelson M, Mock J, Erbaugh J (1961) An inventory for measuring depression. Arch Gen Psychiatry 4:561-571. CrossRef Medline

Beck AT, Epstein N, Brown G, Steer RA (1988) An inventory for measuring clinical anxiety: psychometric properties. Journal of Consulting and Clinical Psychology 56:893-897. CrossRef Medline

Cabeza R, Grady CL, Nyberg L, McIntosh AR, Tulving E, Kapur S, Jennings JM, Houle S, Craik FI (1997) Age-related differences in neural activity during memory encoding and retrieval: a positron emission tomography study. J Neurosci 17:391-400. Medline

Cabeza R, Daselaar SM, Dolcos F, Prince SE, Budde M, Nyberg L (2004) Task-independent and task-specific age effects on brain activity during working memory, visual attention and episodic retrieval. 14:364-375.

Comblain C, D'Argembeau A, Van der Linden M, Aldenhoff L (2004) The effect of ageing on the recollection of emotional and neutral pictures. Memory 12:673-684. CrossRef Medline

Daselaar SM, Veltman DJ, Rombouts SA, Raaijmakers JG, Jonker C (2003) Neuroanatomical correlates of episodic encoding and retrieval in younger and elderly subjects. Brain 126:43-56. CrossRef Medline

Davis SW, Dennis NA, Daselaar SM, Fleck MS, Cabeza R (2008) Que PASA? The posterior-anterior shift in aging. Cereb Cortex 18:1201-1209. CrossRef Medline

Dennis NA, Daselaar S, Cabeza R (2007) Effects of aging on transient and sustained successful memory encoding activity. Neurobiol Aging 28: 1749-1758. CrossRef Medline

D'Esposito M, Deouell LY, Gazzaley A (2003) Alterations in the BOLD fMRI signal with aging and disease: a challenge for neuroimaging. Nat Rev Neurosci 4:863-872. CrossRef Medline

Dew IT, Buchler N, Dobbins IG, Cabeza R (2012) Where is ELSA? The early to late shift in aging. Cereb Cortex 22:2542-2553. CrossRef Medline

Folstein MF, Folstein SE, White T, Messer MA (2010) MMSE-2 MiniMental State Examination user's manual, Ed 2. Lutz, FL: Psychological Assessment Resources.

Ford JH, Kensinger EA (2014) The relation between structural and functional connectivity depends on age and on task goals. Front Hum Neurosci 8:307. CrossRef Medline

Ford JH, Kensinger EA (2016) Effects of internal and external vividness on hippocampal connectivity during memory retrieval. Neurobiol Learn Mem 134:78-90. CrossRef Medline

Ford JH, Morris JA, Kensinger EA (2014a) Effects of emotion and emotional valence on the neural correlates of episodic memory search and elaboration. J Cogn Neurosci 26:825-839. CrossRef Medline

Ford JH, Morris JA, Kensinger EA (2014b) Neural recruitment and connectivity during emotional memory retrieval across the adult life span. Neurobiol Aging 35:2770-2784. CrossRef Medline

Grady CL (2000) Functional brain imaging and age-related changes in cognition. Biol Psychol 54:259-281. CrossRef Medline

Grady CL, Maisog JM, Horwitz B, Ungerleider LG, Mentis MJ, Salerno JA, Pietrini P, Wagner E, Haxby JV (1994) Age-related changes in cortical blood flow activation during visual processing of faces and location. J Neurosci 14:1450-1462. Medline

Grady CL, Bernstein LJ, Beig S, Siegenthaler AL (2002) The effects of encoding task on age-related differences in the functional neuroanatomy of face memory. Psychol Aging 17:7-23. CrossRef Medline

Grossman M, Cooke A, DeVita C, Alsop D, Detre J, Chen W, Gee J (2002) Age-related changes in working memory during sentence comprehension: an fMRI study. Neuroimage 15:302-317. CrossRef Medline 
Hashtroudi S, Johnson MK, Chrosniak LD (1990) Aging and qualitative characteristics of memories for perceived and imagined complex events. Psychol Aging 5:119-126. CrossRef Medline

Huettel SA, Singerman JD, McCarthy G (2001) The effects of aging upon the hemodynamic response measured by functional MRI. Neuroimage 13:161-175. Medline

Hutchinson JL, Lu H, Rypma B (2013) Neural mechanisms of age-related slowing: The $\Delta \mathrm{CBF} / \Delta \mathrm{CMRO}^{2}$ ratio mediates age-differences in BOLD signal and human performance. Cereb Cortex 23:2337-2346. CrossRef Medline

Hutchinson JL, Shokri-Kojori E, Lu H, Rypma B (2013) A BOLD perspective on age-related neurometabolic-flow coupling and neural efficiency changes in human visual cortex. 4:244.

Iidaka T, Okada T, Murata T, Omori M, Kosaka H, Sadato N, Yonekura Y (2002) Age-related differences in the medial temporal lobe responses to emotional faces as revealed by fMRI. Hippocampus 12:352-362. CrossRef Medline

Levine BK, Beason-Held LL, Purpura KP, Aronchick DM, Optican LM, Alexander GE, Horwitz B, Rapoport SI, Schapiro MB (2000) Age-related differences in visual perception: a PET study. Neurobiol Aging 21:577584. CrossRef Medline

Madden DJ, Gottlob LR, Denny LL, Turkington TG, Provenzale JM, Hawk TC, Coleman RE (1999) Aging and recognition memory: changes in regional cerebral blood flow associated with components of reaction time distributions. J Cogn Neurosci 11:511-520. CrossRef Medline

Madden DJ, Turkington TG, Provenzale JM, Denny LL, Langley LK, Hawk TC, Coleman RE (2002) Aging and attentional guidance during visual search: functional neuroanatomy by positron emission tomography. Psychol Aging 17:24-43. CrossRef Medline

Madden DJ, Hoffman JM (1997) Application of positron emission tomography to age-related cognitive changes. In: Brain imaging in clinical psychiatry (Krishnan KRR, Doraiswamy PM, eds), pp 575-613. New York: Marcel Dekker.

Maruff P, Thomas E, Cysique L, Brew B, Collie A, Snyder P, Pietrzak RH (2009) Validity of the CogState brief battery: relationship to standardized tests and sensitivity to cognitive impairment in mild traumatic brain injury, schizophrenia, and AIDS dementia complex. Archives of Clinical Neuropsychology 24:165-178. CrossRef Medline

McLaren DG, Ries ML, Xu G, Johnson SC (2012) A generalized from of context-dependent psychophysiological interactions (gPPI): a comparison to standard approaches. Neuroimage 61:1277-1286. CrossRef Medline

Meulenbroek O, Petersson KM, Voermans N, Weber B, Fernández G (2004) Age differences in neural correlates of route encoding and route recognition. Neuroimage 22:1503-1514. CrossRef Medline

Nyberg L, Sandblom J, Jones S, Neely AS, Petersson KM, Ingvar M, Bäckman L (2003) Neural correlates of training-related memory improvement in adulthood and aging. Proc Natl Acad Sci U S A 100:13728-13733. CrossRef Medline

Park DC, Lautenschlager G, Hedden T, Davidson NS, Smith AD, Smith PK (2002) Models of visuospatial and verbal memory across the adult life span. Psychol Aging 17:299-320. CrossRef Medline

Paxton JL, Barch DM, Racine CA, Braver TS (2008) Cognitive control, goal maintenance, and prefrontal function in healthy aging. Cereb Cortex 18 : 1010-1028. CrossRef Medline

Paxton JL, Barch DM, Storandt M, Braver TS (2006) Effects of environmental support and strategy training on older adults' use of context. Psychol Aging 21:499-509. CrossRef Medline

Rypma B, D'Esposito M (2000) Isolating the neural mechanisms of agerelated changes in human working memory. Nat Neurosci 3:509-515. CrossRef Medline

Salthouse TA (1996) The processing-speed theory of adult age differences in cognition. Psychol Rev 103:403-428. CrossRef Medline

Schaefer A, Philippot P (2005) Selective effects of emotion on the phenomenal characteristics of autobiographical memories. Memory 13:148-160. CrossRef Medline

Sheikh JI, Yesavage JA (1986) Geriatric Depression Scale (GDS): recent evidence and development of a shorter version. In: Clinical gerontology: a guide to assessment and intervention. New York: Haworth.

Shipley WC (1986) Shipley Institute of Living Scale. Los Angeles: Western Psychological Services.

Slotnick SD, Moo LR, Segal JB, Hart J Jr (2003) Distinct prefrontal cortex activity associated with item memory and source memory for visual shapes. Brain Res Cogn Brain Res 17:75-82. CrossRef Medline

Spreen O, Benton AL (1977) Neurosensory Center Comprehensive Examination for Aphasia: manual of instructions. Victoria, BC: University of Victoria.

Talairach J, Tournoux P (1988) Co-planar stereotaxic atlas of the human brain. New York: Thieme Medical.

Taoka T, Iwasaki S, Uchida H, Fukusumi A, Nakagawa H, Kichikawa K, Takayama K, Yoshioka T, Takewa M, Ohishi H (1998) Age correlation of the time lag in signal change on ERP-fMRI. Journal of Computer Assisted Tomography 22:514-517. CrossRef Medline

Tsvetanov KA, Henson RN, Tyler LK, Davis SW, Shafto MA, Taylor JR, Williams N, Cam-Can, Rowe JB (2015) The effect of ageing on fMRI: correction for the confounding effects of vascular reactivity evaluated by joint fMRI and MEG in 335 adults. Hum Brain Mapp 36:2248-2269. CrossRef Medline

Wechsler D (1997) Technical manual for the Wechsler Adult Intelligence Scale, Ed 3. New York: Psychological Corporation.

Wechsler D (1997b) Wechsler Memory Scale, Ed 3. San Antonio, TX: Psychological Corporation. 